\title{
Capsaicin-Induced Ion Fluxes in Dorsal Root Ganglion Cells in Culture
}

\author{
John N. Wood, Janet Winter, lain F. James, Humphrey P. Rang, Jane Yeats, and Stuart Bevan \\ The Sandoz Institute for Medical Research, London WC1E 6BN, England
}

Capsaicin is a pungent pain-producing compound found in plants of the capsicum family; it exerts excitatory, desensitizing, and toxic effects on a subset of sensory neurons, including the polymodal nociceptor population. We have carried out a quantitative study of capsaicin-induced fluxes of sodium, guanidine, calcium, rubidium, and chloride ions in cultures of neonatal and adult rat DRG neurons, in conjunction with the use of a histochemical stain that identifies capsaicin-sensitive neurons by means of cobalt uptake. Those cells that take up cobalt in a capsaicin-dependent manner $\left(E C_{s o}=0.2 \mu \mathrm{M}\right)$ represent about $50 \%$ of the total neuronal population derived from neonatal DRGs on short-term culture. Overnight treatment of cultures with $2 \mu \mathrm{M}$ capsaicin leads to the loss of the cobalt-staining subpopulation. The capsaicin-insensitive neurons contain immunoreactive neurofilament epitopes that are present in fewer than $10 \%$ of capsaicin-sensitive neurons. This observation provides indirect evidence that the sensitive cells correspond to the small, dark B-type neurons, which are negative for neurofilament immunoreactivity in vivo.

A capsaicin-dependent calcium uptake $\left(E C_{50}=0.2 \mu \mathrm{M}\right)$, as measured by ${ }^{45} \mathrm{Ca}$ incorporation, is shown by a DRG neuronal subpopulation that, like the cobalt-staining population of DRG neurons, is lost after overnight capsaicin treatment $(2 \mu \mathrm{M})$. Capsaicin application leads to the accumulation of millimolar levels of calcium within a few minutes. Cadmium and other divalent cations block capsaicin-induced calcium uptake, but little or no inhibition is seen with organic calcium channel antagonists. Mitochondria, rather than the endoplasmic reticulum, are the probable destination of the internalized calcium, because ruthenium red inhibits calcium uptake $\left(I C_{50}=\right.$ $0.05 \mu \mathrm{M})$, whereas methylxanthines are inactive.

The subset of sensory neurons that takes up calcium also releases ${ }^{86} \mathrm{Rb}$ when exposed to capsaicin $\left(E C_{50}=0.06 \mu \mathrm{M}\right)$. No efflux of ${ }^{36} \mathrm{Cl}$ ions could be induced by capsaicin. These cells also show a capsaicin-induced uptake of ${ }^{22} \mathrm{Na}$ or ${ }^{14} \mathrm{C}$ guanidine $\left(E C_{50}=0.06 \mu \mathrm{M}\right)$. In contrast, chick DRG cells in culture showed no capsaicin-induced calcium or cobalt uptake. Primary cultures of rat superior cervical ganglion neurons and Schwann cells, and a number of neuronal cell lines, also failed to respond to capsaicin, as judged by the calcium, cobalt, or guanidine uptake assays.

Received Aug. 3, 1987; revised Nov. 12, 1987; accepted Dec. 23, 1987

We are grateful for expert technical assistance provided by Gordon Ryan, Josephine Hixon, Elsa Phillips, and Alia Minhas. We thank Dr. J. G. Dickson and Professor T. Amano for their gifts of cell lines, and Pat Hogan for helpful discussions.

Correspondence should be addressed to John Wood, The Sandoz Institute for Medical Research, 5 Gower Place, London WC1E 6BN, England.

Copyright (C) 1988 Society for Neuroscience $0270-6474 / 88 / 093208-13 \$ 02.00 / 0$
Capsaicin (8-methyl $N$-vanillyl 6-nonamide), a pungent principle of plants of the capsicum family, has a variety of physiological actions, including perturbation of the cardiovascular and respiratory systems (Jancso and Such, 1983; Lundberg et al., 1985), and pain induction upon topical application to the skin (Carpenter and Lynn, 1981; Kenins, 1982; Konietzny and Hensel, 1983; Szolcsanyi, 1985). Capsaicin-evoked pain may be followed by a period of desensitization to noxious chemical thermal and mechanical stimuli (Hayes and Tyers, 1980; Carpenter and Lynn, 1981; Gamse, 1982; Nagy and van der Kooy, 1983; S7olcsanyi, 1985). Administration of capsaicin to neonatal rats results in the loss of a large proportion of unmyelinated sensory neurons (Jancso et al., 1977; Lawson and Harper, 1984).

The effects of capsaicin are best understood in terms of its excitatory, desensitizing, and toxic actions on a subset of sensory neurons that include the polymodal nociceptor population (Fitzgerald, 1983; Szolcsanyi, 1983; Lynn et al., 1984; Bevan et al., 1987). The actions of low doses of capsaicin seem to be confined to this population of neurons in the periphery, there being few examples of excitatory actions on mechanosensitive or thermosensitive neurons (Coleridge et al., 1965; Lundberg et al., 1985). The basis of the cellular specificity of capsaicin is unknown. It is of considerable interest to understand this selectivity of action, however, as light may be thrown on the mechanism of activation of polymodal nociceptors by other noxious stimuli.

Various effects of capsaicin on sensory neuron subpopulations have been described, mainly through studies on rodents. These actions of capsaicin can be considered in terms of (1) rapid electrophysiological events (Godfraind et al., 1981; Williams and Zieglgansberger, 1982; Baccaglini and Hogan, 1983; Szulcsanyi, 1983; Taylor et al., 1984; Heyman and Rang, 1985), (2) longer-term actions, including effects on neuropeptide levels, axoplasmic transport, and desensitization to subsequent capsaicin application (Gamse et al., 1979, 1982; Lembeck and Gamse, 1982; Priestley et al., 1982; McDougal et al., 1983; Micevych et al., 1983; Handwerker et al., 1984; Szolcsanyi, 1984; Taylor et al., 1984), and (3) irreversible toxic effects leading to the loss of nociceptive afferent neurons, with a variable alteration in thermal and mechanical pain thresholds (Jancso et al., 1977, 1985; Hayes and Tycrs, 1980; Nagy and van der Kooy, 1983; Szolcsanyi, 1985; Hogan, 1988). These effects of capsaicin are dose-dependent and species-dependent, and may also depend on the developmental state of the animal (Jancso et al, 1977, 1985; Petersen et al., 1984; Bevan et al., 1987). Although there is no evidence that capsaicin mimics the action of an endogenous ligand, the tissue and species selectivity of the response to capsaicin, as well as the strict chemical requirements for capsaicin-like activity in a series of analogues (Szolcsanyi 
and Jancso-Gabor, 1975) suggest that a specific interaction between capsaicin and an operationally defined cellular "receptor" must occur.

Electrophysiological studies have revealed a variety of effects of capsaicin on the membrane properties of a range of neuronal types (Godfraind et al., 1981; DuBois, 1982; Erdelyi and Such, 1984). The finding of a strong depolarization associated with a conductance increase in C-type neurons of DRGs (Heyman and Rang, 1985) and in a subpopulation of DRG neurons in culture (Baccaglini and Hogan, 1983) suggests that the specific excitatory effect of capsaicin on nociceptive neurons involves an increase in membrane permeability. To account for the large depolarizations seen, we assume that the ions involved include sodium and/or calcium.

In the present study we have investigated the effects of capsaicin on fluxes of various ions (calcium-45, sodium-22, carbon14 guanidine, rubidium-86, and chloride-36) in cultures of adult and neonatal rat DRG cells. We have used these quantitative assays in conjunction with a histochemical stain for capsaicinsensitive cells (Hogan, 1983) to investigate some aspects of the mechanism of action of capsaicin, with the eventual aim of defining the particular biochemical pathways and structures through which capsaicin acts.

We demonstrate here that a subpopulation of cultured newborn or adult rat DRG neurons shows an increased uptake of calcium, sodium, and guanidinium, and an increased efflux of ${ }^{86} \mathrm{Rb}$, upon treatment with capsaicin. None of a range of cell lines tested show such effects, and other neuronal subtypes, such as rat superior cervical ganglion (SCG) and chick DRG cells in culture, are also unresponsive to capsaicin treatment. These results are discussed within the framework of the known shortterm actions of capsaicin in vivo and in vitro.

\section{Materials and Methods}

\section{Cell culture}

Primary cultures of neonatal rat and chick DRG neurons. DRGs from all spinal levels of neonatal rats were dissected aseptically and collected in Ham's F-14 medium (Imperial Laboratories) supplemented with 1.176 $\mathrm{gm} / \mathrm{liter}$ sodium bicarbonate, $1 \mathrm{~mm}$ glutamine, $100 \mu \mathrm{g} / \mathrm{ml}$ penicillin, and $100 \mathrm{U} / \mathrm{ml}$ streptomycin (Gibco). In some experiments, ganglia were cleaned of spinal nerves and roots under a dissecting microscope. Ganglia were then incubated for $30 \mathrm{~min}$ at $37^{\circ} \mathrm{C}$ in $12 \mathrm{mg} / \mathrm{ml}$ collagenase (Boehringer Mannheim) in F-14 medium. Ganglia were washed in medium, then incubated for a further $30 \mathrm{~min}$ in $2.5 \mathrm{mg} / \mathrm{ml}$ trypsin (Worthington). Ganglia were then washed twice in F-14 medium supplemented with $10 \%$ horse serum (Gibco). The following solution $(0.25$ $\mathrm{ml}$ volumes) was then added to each milliliter of the resuspended ganglia: DNase $1,0.4 \mathrm{mg} / \mathrm{ml}$ (Sigma); soya bean trypsin inhibitor (Sigma), 0.55 $\mathrm{mg} / \mathrm{ml}$; and $\mathrm{MgSO}_{4}, 5 \mathrm{mM}$ in F-14 medium; this was incubated for 30 min. The ganglia were then triturated through a fire-polished Pasteur pipette, filtered through $90 \mu \mathrm{M}$ nylon mesh, spun down, and resuspended in F-14 medium containing 10\% horse serum. The yield of neurons was of the order of 60,000 per animal.

Cells were plated onto Terasaki plates (Flow) previously coated with $10 \mu \mathrm{g} / \mathrm{ml}$ poly-D-lysine or poly-D-ornithine (Sigma; $\left.M_{\mathrm{r}} 150,000\right)$ at a density of 500-1000 neurons/well in F-14 medium containing horse serum diluted $1 / 1$ with $\mathrm{C} 6$-glioma-conditioned medium ( $2 \mathrm{~d}$ on a confluent monolayer), supplemented with $1 \mu \mathrm{g} / \mathrm{ml} \mathrm{NGF}$, the generous gift of Dr. R. M. Lindsay.

Chick DRGs were dissected from 8-12 chick embryos and dissociatcd as for neonatal rat DRGs, except that the collagenase treatment was omitted. The more rapidly adhering non-neuronal cells were depleted from some cultures by preplating for $1 \mathrm{hr}$ on poly-D-ornithine-coated petri dishes. Cells were then plated onto Terasaki plates at a density of 1000 neurons/well in medium composed of Ham's F-14, 10\% horse serum, and $1 \mu \mathrm{g} / \mathrm{ml} \mathrm{NGF}$.

Adult $D R G$ cultures. Adult rats (older than 2 months) were anesthe- tized with pentobarbitone $(0.6 \mathrm{mg} / \mathrm{kg}$, i.p. $)$, and the spinal columns were removed aseptically. These were pinned dorsal-side up and spinal cords exposed with bone-cutting forceps. Ganglia were then removed from all spinal cord levels and pooled in F-14 medium containing 10\% horse serum. Spinal nerves and roots and connective tissue sheaths were removed. Ganglia were then incubated in F-14 medium containing 10\% horse serum and $12 \mathrm{mg} / \mathrm{mll}$ collagenase for $90 \mathrm{~min}$, followed by a further $90 \mathrm{~min}$ incubation in fresh collagenase-containing medium. This step was carried out at $37^{\circ} \mathrm{C}$ in a humidified atmosphere containing $3 \% \mathrm{CO}_{2}$. The ganglia were then washed 3 times in F-14 medium, digested with $2.5 \mathrm{mg} / \mathrm{ml}$ trypsin for $30 \mathrm{~min}$ at room temperature, and then washed 3 times with medium containing $10 \%$ horse serum. Cells were counted and plated out as described for neonatal DRG cultures, except that cells were usually preplated overnight on petri dishes coated with poly-Dornithine (Sigma) in order to reduce the large number of non-neuronal cells. They were then mechanically removed from these dishes and replated onto poly-D-ornithine-coated petri dishes treated with $5 \mu \mathrm{g} / \mathrm{ml}$ laminin (BRL). Conditioned medium and NGF were unnecessary for the primary culture of adult cells (Lindsay 1987).

Superior cervical ganglion and Schwann cell cultures from neonatal rats. SCG and sciatic nerves were removed aseptically from nconatal rats and dissociated as described above for the DRG preparation. SCG cells were grown in conditions similar to those for neonatal DRG cells. Cells derived from sciatic nerve (mainly Schwann cells and fibroblasts) were plated at a density of 2000-3000 cells/well in Terasaki plates and grown in F-14 medium supplemented with antibiotics and 10\% fetal calf serum (FCS).

Neuronal cell lines. All cells lines, including neuroblastoma $\times$ DRG hybrid cell lines and neuroblastoma $\times$ embryonal carcinoma hybrid cells, were grown in Dulbecco's modified Eagle's medium (DMEM; Gibco), supplemented with 10\% FCS and antibiotics (Penicillin, 100 $\mathrm{U} / \mathrm{ml}$, and streptomycin, $100 \mu \mathrm{g} / \mathrm{ml}$; Flow). Cells were differentiated for $7 \mathrm{~d}$ by the addition of $1 \mathrm{~mm}$ dibutyryl-cAMP (Sigma) or $1 \mu \mathrm{M}$ retinoic acid (Sigma), or by reducing the concentration of FCS to $2 \%$ (Hamprecht, 1977; Webb et al., 1986).

\section{Histochemical stain for capsaicin action (Hogan 1988)}

Terasaki plates of neonatal DRGs from 2 to $20 \mathrm{~d}$ in vitro (DIV) were washed 6 times with assay buffer $\left[\mathrm{KCl}, 5 \mathrm{~mm} ; \mathrm{MgCl}_{2}, 2 \mathrm{~mm}\right.$; glucose, $12 \mathrm{~mm}$; HEPFS, pH 7.4 (with $\mathrm{KOH}$ ), $10 \mathrm{~mm}$; sucrose, $137 \mathrm{~mm} ; \mathrm{NaCl}$ $5.8 \mathrm{~mm}$; and $\mathrm{CaCl}_{2}, 0.75 \mathrm{~mm}$. Assay buffer containing $5 \mathrm{~mm} \mathrm{CoCl}_{2}$, with or without capsaicin diluted from a $20 \mathrm{~mm}$ stock in dimethyl sulfoxide (DMSO) or ethanol, was then added to each well. After an incubation for $8 \mathrm{~min}$ at room temperature, the plates were washed 4 times with assay buffer and then treated for $5 \mathrm{~min}$ at room temperature with a $1.2 \%(\mathrm{vol} / \mathrm{vol})$ solution of ammonium polysulfide (BDH) in assay buffer. The plates were then washed a further 4 times in assay buffer before fixation with paraformaldehyde (4\% wt/vol in PBS) or glutaraldehyde ( $4 \% \mathrm{wt} / \mathrm{vol}$ in PBS). At this stage, the plates could be stored at $4^{\circ} \mathrm{C}$ or processed further. Plates were washed 3 times in assay buffer, then twice with incomplete developer (hydroquinone, $15 \mathrm{~mm}$; citric acid, $38 \mathrm{~mm}$; sucrose, $280 \mathrm{~mm}$ ), and warmed to $50^{\circ} \mathrm{C}$. The plates were then incubated for approximately $15 \mathrm{~min}$ at $50^{\circ} \mathrm{C}$ with 2 changes of complete developer [1 volume of $1 \%$ (wt/vol) $\mathrm{AgNO}_{3}$ in water/9 volumes of incomplete developer]. The level of development of cobalt stain was examined microscopically, and the reaction stopped by washing twice with incomplete developer, followed by further washings with assay buffer.

\section{Calcium-45 uptake experiments}

Terasaki plates of cultured DRG neurons $(\sim 1000$ neurons/well) were equilibrated with 6 washes of HEPES ( $10 \mathrm{~mm}$, pH 7.4)-buffered calcium and magnesium-free Hanks' balanced salt solution, to which up to 2 $\mathrm{mm} \mathrm{CaCl}{ }_{2}$ was added. The solution in each well was then replaced with the same buffer, containing $10 \mu \mathrm{Ci} / \mathrm{ml}{ }^{45} \mathrm{Ca}(60 \mathrm{Ci} / \mathrm{mmol}$; Amersham) in the presence and absence of capsaicin for $10 \mathrm{~min}$ at room temperature. The assay was stopped by washing the plates in assay buffer 6 times, followed by evaporation of residual buffer in the wells at $70^{\circ} \mathrm{C}$ for 15 min. SDS, $0.1 \%(10 \mu \mathrm{l})$ was then added to each well to extract the calcium-45. This was then removed and counted in $1 \mathrm{ml}$ of Beckman CP scintillant.

Some calcium accumulation assays were carried out in sodium-free buffer containing isoosmotic sucrose, as used in the guanidinium uptake assays described below. All reagents were obtained from Sigma, unless otherwise indicated. 


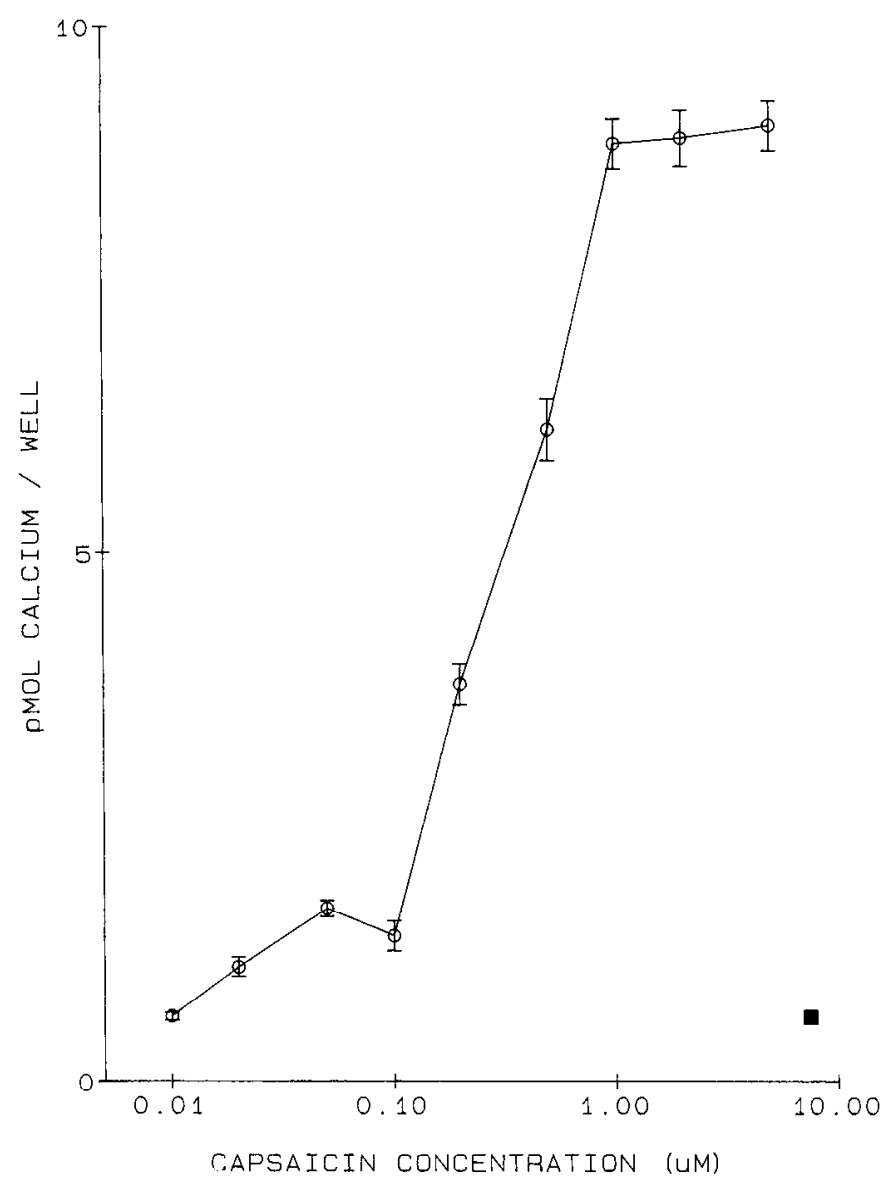

Figure 1. Capsaicin-induced calcium uptake into neonatal rat DRG neurons in culture. Calcium accumulation into neonatal rat DRG cells in culture was measured by means of ${ }^{45} \mathrm{Ca}$ at concentrations of capsaicin from 0 to $10 \mu \mathrm{M}$. A single representative experiment is shown (3-5 DIV; $n=10) . \mathrm{EC}_{{ }_{0}}=0.2 \mu \mathrm{M}$. Black square, background uptake.

\section{Guanidine efflux and sodium uptake assays}

Terasaki plates of neonatal DRGs, cultured from 2 to 15 DIV, were gently washed in the following buffer: sucrose, $290 \mathrm{~mm}$; HEPES, $10 \mathrm{~mm}$, pH 7.4 (with $\mathrm{KOH}$ ); glucose, $20 \mathrm{~mm}$; and $\mathrm{KCl}, 5.4 \mathrm{~mm}$. The medium was changed to one containing ${ }^{22} \mathrm{Na}$ chloride $(20 \mu \mathrm{Ci} / \mathrm{ml}$; sp act, $\sim 20$ $\mathrm{Ci} / \mathrm{mmol}$ ) (Amersham) with or without capsaicin. After 90 sec, the plates were washed rapidly in buffer, and radioactivity in individual wells was then counted in SDS as described above. ${ }^{14} \mathrm{C}$-Guanidine efflux experiments were carried out on cells labeled for $2 \mathrm{hr}$ in growth medium containing $10 \mu \mathrm{Ci} / \mathrm{ml}^{14} \mathrm{C}$ guanidine, as described below for rubidium86 efflux experiments, except that samples were counted in $10 \mathrm{ml}$ Beckman CP scintillant.

\section{Rubidium-86 efflux}

Terasaki plates of cultured DRG cells were incubated for $2 \mathrm{hr}$ in growth medium containing $2 \mu \mathrm{Ci} / \mathrm{ml}^{86} \mathrm{Rb}(\sim 300 \mathrm{mCi} / \mathrm{mmol} ;$ Amersham $)$. The plates were then washed 3 times, followed by 2 further washes at 5 min intervals with HEPES-buffered DMEM. The medium on the plates $(9$ $\mathrm{ml}$ ) was then changed at $1 \mathrm{~min}$ intervals, each sample being collected in a scintillation vial. After 8 consecutive changes, DMEM containing capsaicin was added for 2 consecutive washes, followed by 3 further washes with DMEM. The counts remaining in the cells were measured after dissolution in $0.2 \%$ SDS. Radioactivity was measured in a liquid scintillation counter without added scintillant. The rate of ${ }^{86} \mathrm{Rb}$ efflux was expressed as a rate constant by calculating the amount of ${ }^{86} \mathrm{Rb}$ released in each 1 min interval as a fraction of the amount of ${ }^{86} \mathrm{Rb}$ present in the cells at the beginning of the collection period.

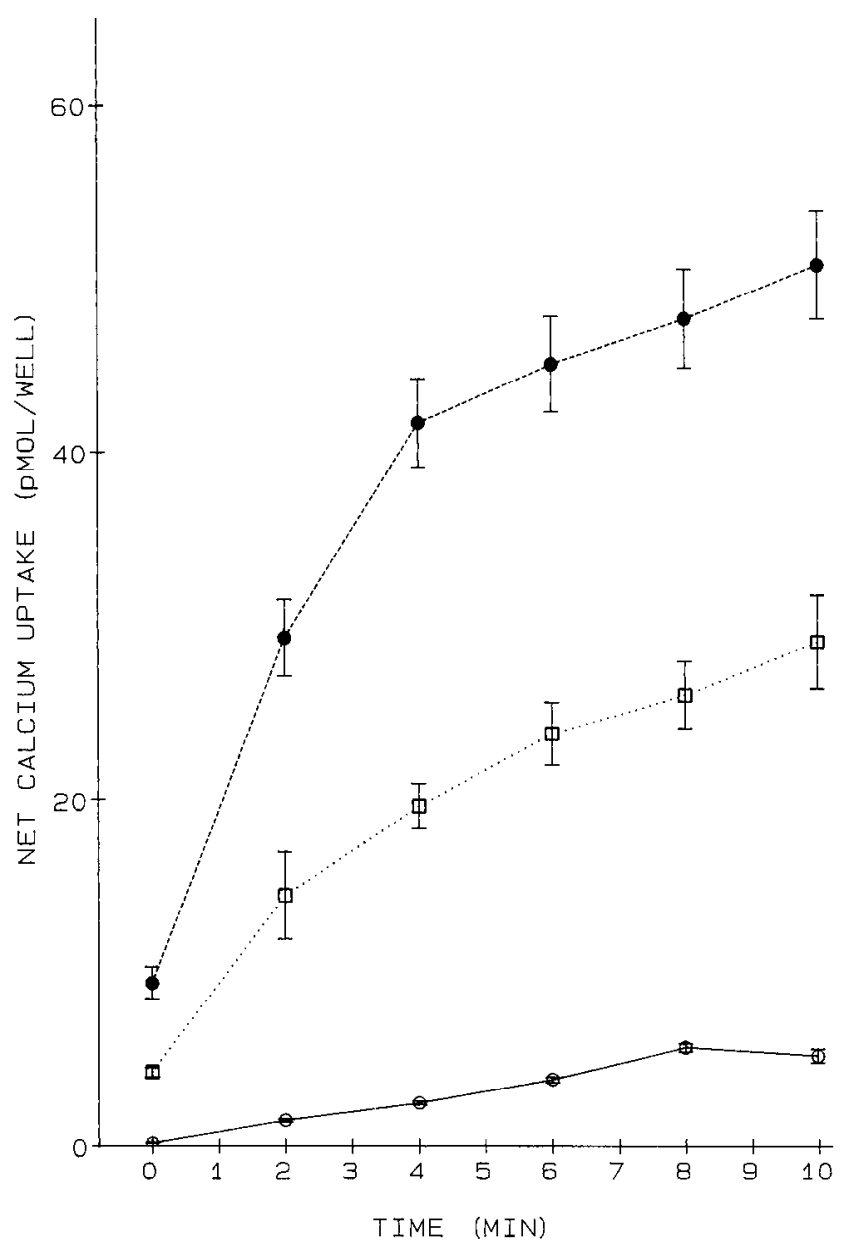

Figure 2. Rate of capsaicin-induced uptake of calcium in different concentrations of external calcium. Rates of uptake of calcium into neonatal rat DRG cells (3-5 DIV) in culture were measured using ${ }^{45} \mathrm{Ca}$ in different external concentrations of calcium. Cells were stimulated with $2 \mu \mathrm{M}$ capsaicin. Uptake is presented as calcium (in pmol)/well, where each well contains 500-2000 capsaicin-sensitive neurons. The numbers of neurons was constant within any single experiment. Calcium uptake in the presence of $15 \mu \mathrm{M}(-\infty), 0.3 \mathrm{mM}(\cdots \cdots \cdots)$, or $2 \mathrm{mM}$ (-------) external calcium. Background levels of calcium accumulation were subtracted from each uptake curve to give net uptake rates. Data are means and standard errors from 3 experiments.

\section{Chloride-36 efflux}

Terasaki plates of DRGs were labeled with ${ }^{36} \mathrm{Cl}(10 \mu \mathrm{Ci} / \mathrm{ml}$; sp act, 10 $\mathrm{mCi} / \mathrm{mmol}$ ) (Amersham) overnight in growth medium. The procedure for efflux studies was essentially the same as that described above for rubidium efflux. Samples were counted in Redisolve CP scintillant (Beckman) in a liquid scintillation counter.

\section{Immunofluorescence double-labeling}

The cobalt assay was carried out as described on petri dishes containing adult DRG neurons (3 DIV), except that $4 \%$ (wt/vol) paraformaldehyde was used as a fixative. Dishes were then washed in PBS $(\mathrm{NaCl}, 0.14 \mathrm{M}$ $\mathrm{KCl}, 2.7 \mathrm{~mm} ; \mathrm{KH}_{2} \mathrm{PO}_{4}, 1.5 \mathrm{~mm} ; \mathrm{Na}_{2} \mathrm{HPO}_{4}, 8.1 \mathrm{~mm}$ ) with $0.1 \%$ Triton $\mathrm{X}-100(\mathrm{BDH})$ for $5 \mathrm{~min}$, followed by PBS containing $0.1 \%$ Triton X-100 and $10 \%$ FCS (Gibco) for a further $5 \mathrm{~min}$. RT97 monoclonal antibody ascites fluid (Wood and Anderton, 1981; Lawson et al., 1984) was diluted 1:2000 in the PBS/Triton X-100/FCS and applied to the cultures for $30 \mathrm{~min}$. After washing, rhodamine-conjugated rabbit anti-mouse immunoglobulin (1:100; Miles) was applied for a further $30 \mathrm{~min}$. Dishes were washed, mounted in a commercial mountant that minimizes fading (Citifluor), and examined with a Nikon Fluophot microscope equipped with epifluorescence and phase-contrast optics. 


\section{Results}

\section{Capsaicin-induced calcium uptake}

Capsaicin increased the amount of ${ }^{45} \mathrm{Ca}$ accumulated by cultures of neonatal rat DRG neurons. The dose-response curves showed a maximum uptake of up to 20 times the control value, with about $1 \mu \mathrm{M}$ capsaicin and an $\mathrm{EC}_{50}$ value of $0.2 \mu \mathrm{M}$ (Fig. 1).

Both the rate of calcium uptake and the maximum amount of calcium accumulated increased with increasing concentrations of extracellular calcium (Fig. 2). The rate of accumulation was approximately linear with time up to $10 \mathrm{~min}$ for low (micromolar) concentrations of external calcium, whereas with higher (millimolar) levels of calcium, the accumulation rate slowed with time. Variation of the extracellular calcium concentration over the range $15 \mu \mathrm{M}$ to $2 \mathrm{mM}$ had little or no effect on the estimated $\mathrm{EC}_{50}$ for capsaicin $\left(\mathrm{EC}_{50} \sim 0.2 \mu \mathrm{M}\right.$; data not shown). Calculation of the intracellular volume of neuronal somata from measurements of their diameter (with the assumption that the cell bodies are spherical, and that $50 \%$ of the neurons are capsaicin-sensitive) allows an approximate estimate of the absolute level of calcium uptake to be made. The amount of calcium taken up, expressed as an ovcrall concentration, ranged from 2 $\mathrm{mM}$ in low $(15 \mu \mathrm{M})$ external calcium, through $6 \mathrm{~mm}$ in $300 \mu \mathrm{M}$ external calcium, to $12 \mathrm{~mm}$ when the cells were incubated at a physiological concentration of calcium ( $2 \mathrm{~mm})$. These values represent the average concentration of calcium in the susceptible cell population, but it is presumed that most of the calcium is sequestered by intracellular organelles, particularly by mitochondria (see below).

The rate of capsaicin-induced calcium accumulation increased as a function of temperature between 0 and $45^{\circ} \mathrm{C}$, but the effect at $37^{\circ} \mathrm{C}$ was only about double that at $0^{\circ} \mathrm{C}$, and there was little difference between the rates of uptake at room temperature $\left(\sim 21^{\circ} \mathrm{C}\right)$ and $37^{\circ} \mathrm{C}$. Variation of the extracellular $\mathrm{pH}$ over the range of 6.8-8.0 also had little or no effect on the capsaicin-stimulated calcium uptake.

We attempted to identify the site of the accumulated calcium. The capsaicin-induced calcium uptake seen in low $(10 \mu \mathrm{M})$ calcium media was totally inhibited when cells were coincubated with a low concentration of the calcium ionophore A23187 (1 $\mu \mathrm{M})$. A23187 alone had no measurable effect on the relatively insensitive calcium accumulation assay, presumably because the concentration of intracellular calcium rises to only micromolar levels, and vesicular calcium buffering is compromised by the ionophore. However, addition of A23187 (1-5 $\mu \mathrm{M})$ to cultures that had previously been exposed to capsaicin in the presence of ${ }^{45} \mathrm{Ca}$ led to the release of $70 \pm 6 \%$ (mean $\pm \mathrm{SD}$ ) of the accumulated calcium within $1 \mathrm{~min}$. Thus the accumulated calcium is, in large part, present in a pool that can be readily mobilized.

The effects of inhibitors of calcium uptake into mitochondria and endoplasmic reticulum were also examined. The methylxanthines caffeine and isobutylmethylxanthine (0.1-10 $\mathrm{mm}$ ), which are known to block the intracellular buffering of calcium by endoplasmic reticulum in DRG neurons (Neering and McBurney, 1984), had no effect on capsaicin-induced calcium uptake. By contrast, agents that interfere with mitochondrial calcium uptake did show an effect. Ruthenium red has effects on calcium transport in plasma membranes (Wieraszko, 1986) and on mitochondria, in which it acts to mobilize calcium stores and to block further calcium uptake (Broekemeier et al., 1985; Baker and Umbach, 1987). Coincubation with low concentra-
Table 1. Effect of divalent cations on capsaicin-induced calcium uptake into neonatal rat DRG neurons in culture

\begin{tabular}{lc} 
Cation & $\mathrm{IC}_{50}(\mu \mathrm{M})$ \\
\hline $\mathrm{Mg}$ & 1000 \\
$\mathrm{Mn}$ & 630 \\
$\mathrm{Sr}$ & 300 \\
$\mathrm{Ba}$ & 230 \\
$\mathrm{Co}$ & 200 \\
$\mathrm{Ni}$ & 70 \\
$\mathrm{Cd}$ & 4
\end{tabular}

Experiments were carried out in HEPES-buffered Hanks' solution containing 100 $\mu \mathrm{M}$ calcium, $10 \mu \mathrm{Ci} / \mathrm{ml}^{45} \mathrm{Ca}$ at room temperature for $10 \mathrm{~min}$, as described in the text.

tions of ruthenium red $\left(\mathrm{IC}_{50}=50 \mathrm{nM}\right)$ blocked the capsaicininduced calcium uptake. Similarly, pretreatment of the cultures with the uncoupler of oxidative phosphorylation, carbonyl cyanide $p$-trichloromethoxy-phenylhydrazone (CCCP; $10 \mu \mathrm{M}$ ) completely inhibits accumulation. A mixture of sodium azide and potassium cyanidc (both at $1 \mathrm{~mm}$ ) reduced the amount of calcium accumulated by $69 \pm 15 \%$ (mean \pm SD), while oligomycin $(50 \mu \mathrm{g} / \mathrm{ml}$ of oligomycin $\mathrm{A}, \mathrm{B}$, and $\mathrm{C})$, which acts at the level of the mitochondrial ATPase, lowered uptake by 40 $\pm 21 \%$ (mean $\pm \mathrm{SD}$ ). These results are consistent with the notion that the principal location of the accumulated calcium is in the mitochondrion, where it is stored in a form that can be readily released by ionophores such as A23187.

It is known that membrane depolarization can induce calcium uptake by opening voltage-sensitive calcium channels (for review, see Miller, 1987b). Since capsaicin depolarizes C-type sensory neurons (Baccaglini and Hogan, 1983; Heyman and Rang, 1985), it is possible that the increased calcium uptake occurred by this mechanism, rather than by a primary action on membrane permeability. We tested this in 2 ways; first, by measuring the effect of various divalent cations and organic antagonists of known calcium channels on the capsaicin-induced calcium uptake; second, by comparing the maximum calcium uptake produced by $\mathrm{K}^{+}$depolarization with that evoked by capsaicin. Table 1 shows that some divalent cations were able to inhibit the capsaicin-induced calcium uptake $\left(\mathrm{Cd}^{2+} \gg \mathrm{Ni}^{2+}>\right.$ $\mathrm{Co}^{2+} \approx \mathrm{Ba}^{2+}>\mathrm{Sr}^{2+}>\mathrm{Mn}^{2+}$, although magnesium had little or no effect. The organic calcium channel antagonists verapamil and nifedipine $(\leq 100 \mu \mathrm{M})$ and $\omega$-conotoxin $(\leq 100 \mu \mathrm{g} / \mathrm{ml})$ failed to block the capsaicin effect, irrespective of the calcium concentration in the medium (10 $\mu \mathrm{M}-2 \mathrm{mM})$. Cinnarizine, a diphenylpiperazine blocker of calcium channels, was inactive at $100 \mu \mathrm{M}$ when added to the culture at the same time as capsaicin, but with a preincubation time of $30 \mathrm{~min}$, inhibited the capsaicininduced uptake $\left(\mathrm{IC}_{50}=10 \mu \mathrm{M}\right)$. Trifluoperazine, a calcium $/ \mathrm{cal}$ modulin antagonist that also inhibits phospholipase $\mathrm{A}_{2}$ (Broekemeier et al., 1985) and blocks calcium entry into some cells by an intracellular action (Godfraind, 1987) inhibited the capsaicin-induced calcium uptake with an $\mathrm{IC}_{50}$ of $35 \mu \mathrm{M}$.

Depolarization of the DRG neurons with $50 \mathrm{mM} \mathrm{KCl}$ produced a small $(60 \pm 31 \%$, mean \pm SD) increase in the accumulation of calcium. Accumulation was further increased to $100 \pm 50 \%$ (mean \pm SD) when $1 \mu \mathrm{M}$ Bay K 8644, a calcium channel "agonist" (Schramm et al., 1983), was added to the high-potassium solution. This depolarization-induced rise in calcium uptake is small compared to the 10-20-fold increase 

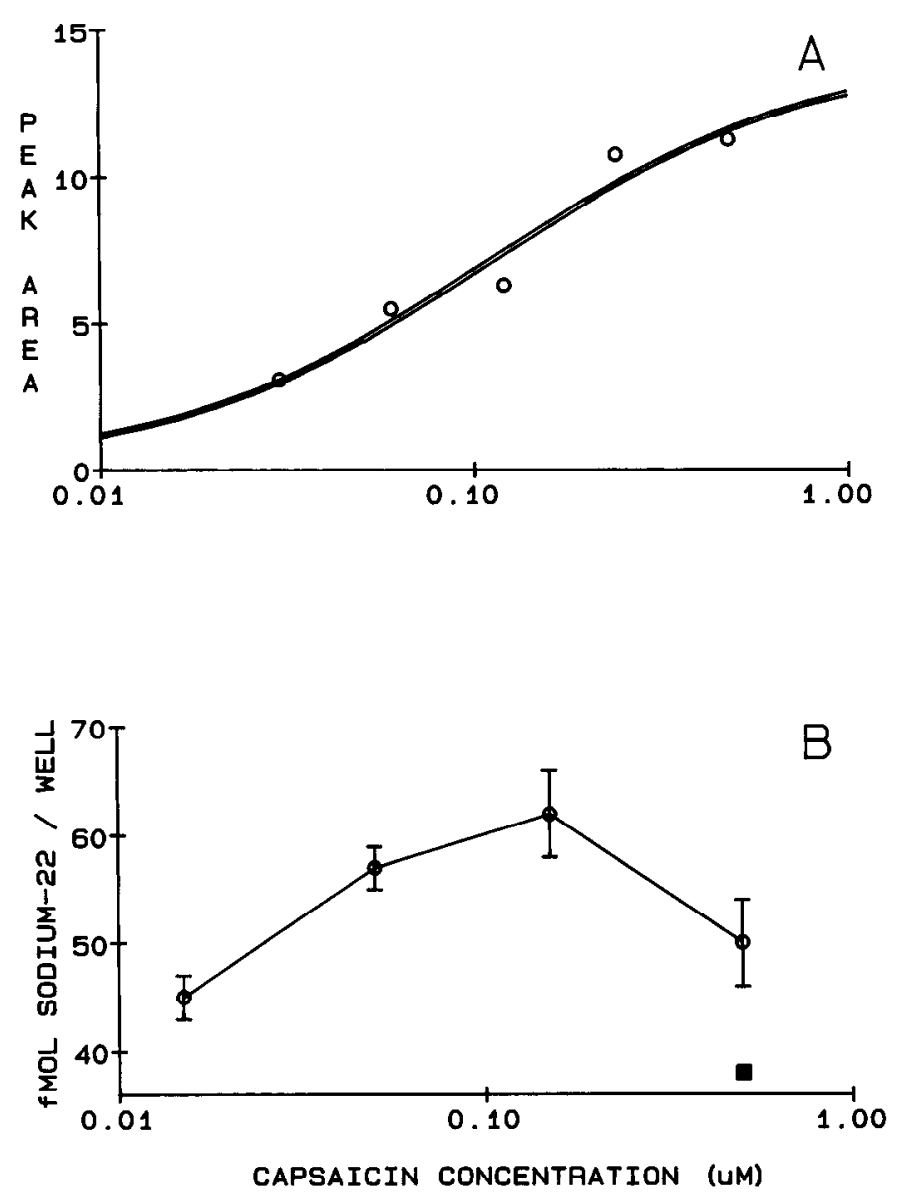

Figure 3. Capsaicin-induced sodium uptake and guanidine efflux from neonatal rat DRG neurons in culture. $A, \mathrm{C}-14$ guanidine emux from preloaded DRG neurons (6 DIV) as a function of capsaicin concentration. Efflux experiments were carried out as described for Figure 5, and peak areas integrated and plotted (arbitrary units) against capsaicin concentration $\left(\mathrm{EC}_{50}=0.06 \mu \mathrm{M}\right) . B$, Na-22 uptake in HEPES-buffered isoosmotic sucrose. $\mathrm{EC}_{50}=0.05 \mu \mathrm{M}$. Background uptake is shown as a filled square. A single representative experiment is shown (cultures $=4$ DIV). Results are expressed as uptake (fmol)/well, where the number of cells per well is from 500 to 2000 .

produced by capsaicin. The major effect of capsaicin is, therefore, not simply due to the opening of voltage-activated calcium channels.

The effects of a variety of putative excitatory compounds, inflammatory mediators, and second messengers on ${ }^{45} \mathrm{Ca}$ uptake into DRG neurons were measured. Under the conditions of our assay, which measured net calcium accumulation rather than the influx rate, no agent tested within the dose range $0.01 \mu \mathrm{M}$ to $1 \mathrm{~mm}$ (epinephrine, norepinephrine, dopamine, 3-methoxyDOPA, vanillylamine, homovanillic acid, 3-methoxy 4-hydroxy phenylglycol, 3-methoxy 4-hydroxy mandellic acid, 3-methoxy tyramine, 3-methoxy-D,L, tyrosine, serotonin, prostaglandin D2, prostaglandin E2, platelet activating factor (PAF), zingerone, mustard oil, sinigrin, substance $P$, glutamate, ATP, dibutyryl cAMP, dibutyryl cGMP, A23187) evoked a capsaicin-like response. However, depolarization with $50 \mathrm{~mm} \mathrm{KCl}$ in the presence of $1 \mu \mathrm{M}$ Bay K 8864, a calcium channel agonist, evoked twice the background uptake of calcium (2.0-fold; $\mathrm{SD}=0.5)$. Among the compounds found to be inactive in this assay were a variety of catecholamine metabolites with structural similar- ities to capsaicin. Several known analgesic compounds (acetaminophen, 2-D-Ala 5-D-Leu enkephalin, dynorphin A) were also tested for their ability to inhibit the capsaicin-evoked calcium uptake. Of the tested compounds, only eugenol, the mild analgesic ingredient of oil of cloves that exhibits some structural similarity to capsaicin, showed antagonism $\left(\mathrm{IC}_{50}=250-500 \mu \mathrm{M}\right)$, with a total inhibition of calcium uptake by an $\mathrm{EC}_{50}$ dose of capsaicin $(0.2 \mu \mathrm{M})$ at concentrations above $1 \mathrm{~mm}$.

\section{Sodium and guanidine fluxes}

Capsaicin increased the amount of ${ }^{22} \mathrm{Na}$ taken up by DRG cultures over a $90 \mathrm{sec}$ period by a factor of up to 2 . Similarly, the uptake of ${ }^{14} \mathrm{C}$ guanidine, which is known to permeate certain sodium channels, such as voltage-sensitive sodium channels (Kao and Nishiyama, 1965), was also raised by a factor of up to 2 when capsaicin was added to the medium. The $\mathrm{EC}_{50}$ for capsaicin-induced sodium influx assays was approximately 0.06 $\mu \mathrm{M}$ (Fig. $3 B$ ), which is somewhat lower than that for the accumulation of calcium or cobalt (see below). ${ }^{14} \mathrm{C}$ guanidine influx assays were also performed in the presence of physiological ( 2 $\mathrm{mm}$ ) levels of calcium. Under these conditions, both the background and capsaicin-evoked guanidine influxes were reduced by $\sim 50 \%$, the ratio of evoked to control uptake being unaffected.

Because the sodium and guanidinium uptake assays gave weak signals, we measured the rate of efflux of ${ }^{14} \mathrm{C}$ guanidine from prelabeled neurons in the presence of varying amounts of capsaicin (Fig. 3A). Using this assay, the $\mathrm{EC}_{50}$ for capsaicin-induced guanidine efflux was calculated to be $0.07 \mu \mathrm{M}$, supporting the figure determined in the uptake assays.

\section{Rubidium eflux}

${ }^{86} \mathrm{Rb}$ is known to be permeant in a variety of potassium channels, and can be used as a convenient measure of potassium flux. In both low (10 $\mu \mathrm{M})$ - and high ( $2 \mathrm{mM})$-calcium solutions, capsaicin evokes a dose-dependent efflux of ${ }^{86} \mathrm{Rb}$, with an $\mathrm{EC}_{50}$ of 0.06 $\mu \mathrm{M}$ (Fig. $4 A$ ). The ${ }^{86} \mathrm{Rb}$ efflux is inhibited but not abolished in calcium-free EGTA containing Hanks' solution (not shown). The ${ }^{86} \mathrm{Rb}$ efflux is, however, abolished (Fig. $4 B$ ) when DRG cultures are first treated overnight with $2 \mu \mathrm{M}$ capsaicin (see below).

\section{Chloride efflux}

Under conditions in which GABA $(50 \mu \mathrm{M})$ evoked an efflux of ${ }^{36} \mathrm{Cl}$ from cultures of DRG neurons, no capsaicin-evoked chloride efflux could be demonstrated.

\section{Cellular specificity of action}

Histochemical detection of capsaicin-sensitive neurons. Capsaicin, under appropriate conditions, will inducc thc uptake of cobalt into sensitive cells (Hogan, 1983). The intracellular cobalt may then be precipitated as the sulfide and visualized either directly or after enhancement with a silver-based stain. We analyzed the percentage of capsaicin-responsive cells in culture by means of this histochemical stain. The percentage of stained cells increased with the concentration of capsaicin, with an $\mathrm{EC}_{50}$ of about $0.2 \mu \mathrm{M}$ (see Fig. 5).

In 2-d-old cultures of neonatal rat DRG cells, a maximum of $\sim 50 \%$ of the neurons was stained after exposure to $2 \mu \mathrm{M}$ capsaicin. A higher percentage of stained neurons (up to $90 \%$ at 21 DIV) was noted after longer periods in culture, in agreement with earlier electrophysiological studies (Baccaglini and Hogan, 1983). 


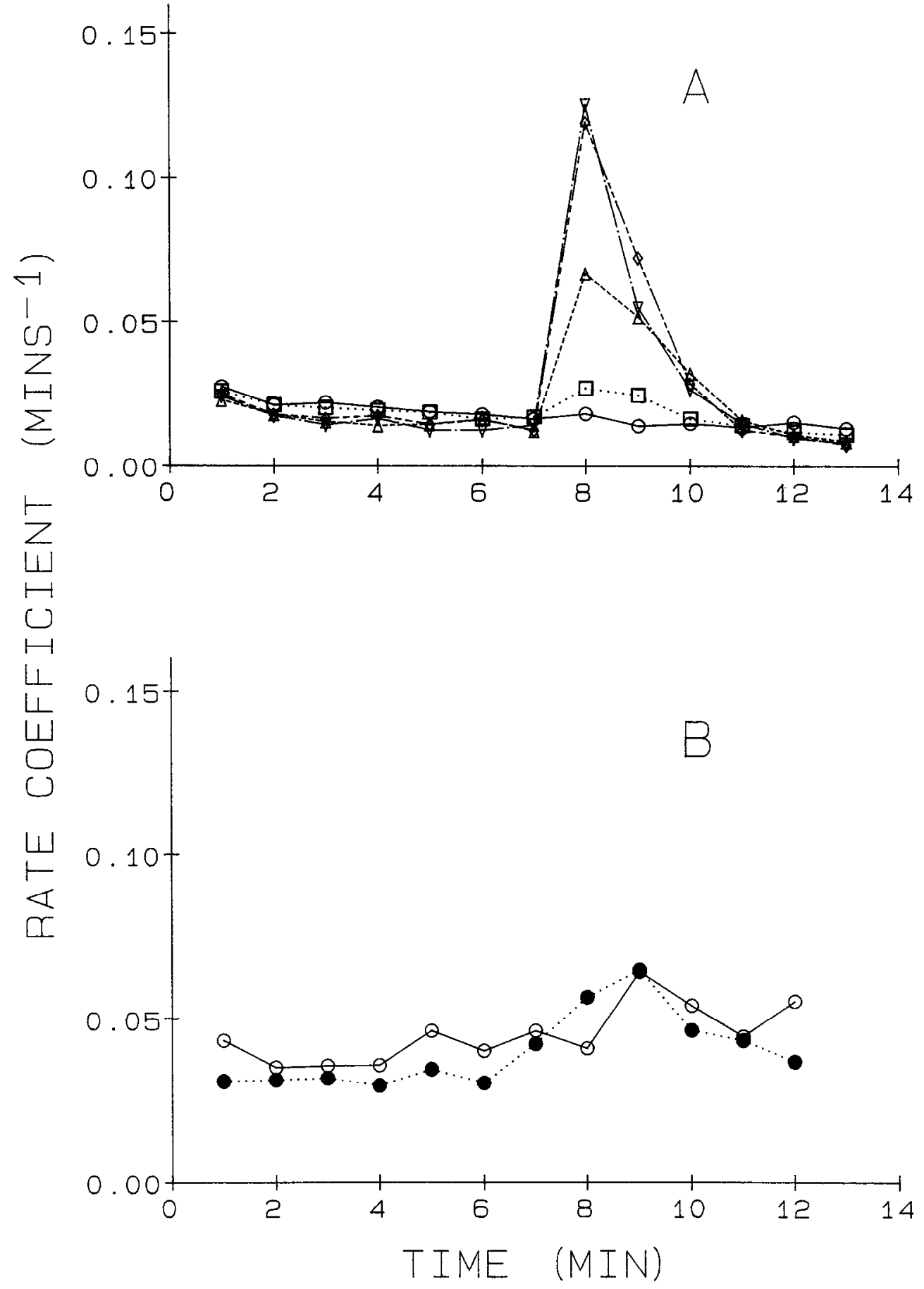

Figure 4. Capsaicin-induced rubidium-86 efflux from neonatal DRG cells in culture. $A$, Efflux of ${ }^{86} \mathrm{Rb}$ from neonatal rat DRG cultures (7 DIV) preloaded with ${ }^{86} \mathrm{Rb}$, treated with varying concentrations of capsaicin for 6-8 min. $(-0-)$, Control efflux; $(\cdots \cdots \square \cdot \cdots)$, $0.02 \mu \mathrm{M}$ capsaicin; $(-\cdot---\triangle-\cdot---), 0.06$ $\mu \mathrm{M}$ capsaicin; $\left(-\diamond_{-}\right), 0.2 \mu \mathrm{M}$ capsaicin; $(-\cdots \nabla-\cdots), 0.6 \mu \mathrm{M}$ capsaicin. $\mathrm{EC}_{50}=$ $0.06 \mu$ M. $B$, Efflux of ${ }^{86} \mathrm{Rb}$ from neonatal rat cultures (5 DIV) treated overnigh with $2 \mu \mathrm{M}$ capsaicin. (-O-), Control efflux; $(\cdots \cdots \cdots)$, efflux in the presence of $2 \mu \mathrm{M}$ capsaicin from 6 to $8 \mathrm{~min}$.
The cobalt-staining method was also used to compare the subpopulation of capsaicin-sensitive cells with known subtypes of DRG neurons, as defined by their neurofilament content. Cultures of adult rat DRG neurons were processed for capsaicininduced cobalt uptake, fixed, and then stained with a monoclonal antibody (RT97) that recognizes a phosphorylated neurofilament epitope (Wood and Anderton, 1981; Lawson et al., 1984). Only $5 \%$ of the RT 97 -stained cells (RT $97^{+}$) showed cobalt uptake, whereas cobalt precipitate was noted in $50 \%$ of the neurons that did not stain with this antibody. Overall, $>98 \%$ of the capsaicin-sensitive cells could be classed as RT97-.

Figure 6 shows a typical RT $97^{+} /$capsaicin-insensitive large neuron and a smaller RT97-/capsaicin-sensitive cell. These re- sults agree well with those of Lawson and Harper (1984), who found that neonatal capsaicin treatment resulted in preferential loss of a population of small, dark RT97- neurons in adult rat DRG. A more detailed report of these experiments is given elsewhere (Winter, 1987).

"Capsaicin-killed" cultures. Cultures exposed for long periods (e.g., overnight) to $2 \mu \mathrm{M}$ capsaicin showed little or no subsequent capsaicin-induced cobalt uptake (Fig. 7). Such prolonged exposure also resulted in a reduction in the number of neurons in the culture. Capsaicin-treated cultures lost $37 \pm 2 \%$ (mean \pm $\mathrm{SD}$ ) of their neurons, which is similar to the percentage of capsaicin-sensitive, cobalt-stained neurons in control cultures. This result is consistent with the known cytotoxic effects of capsaicin 


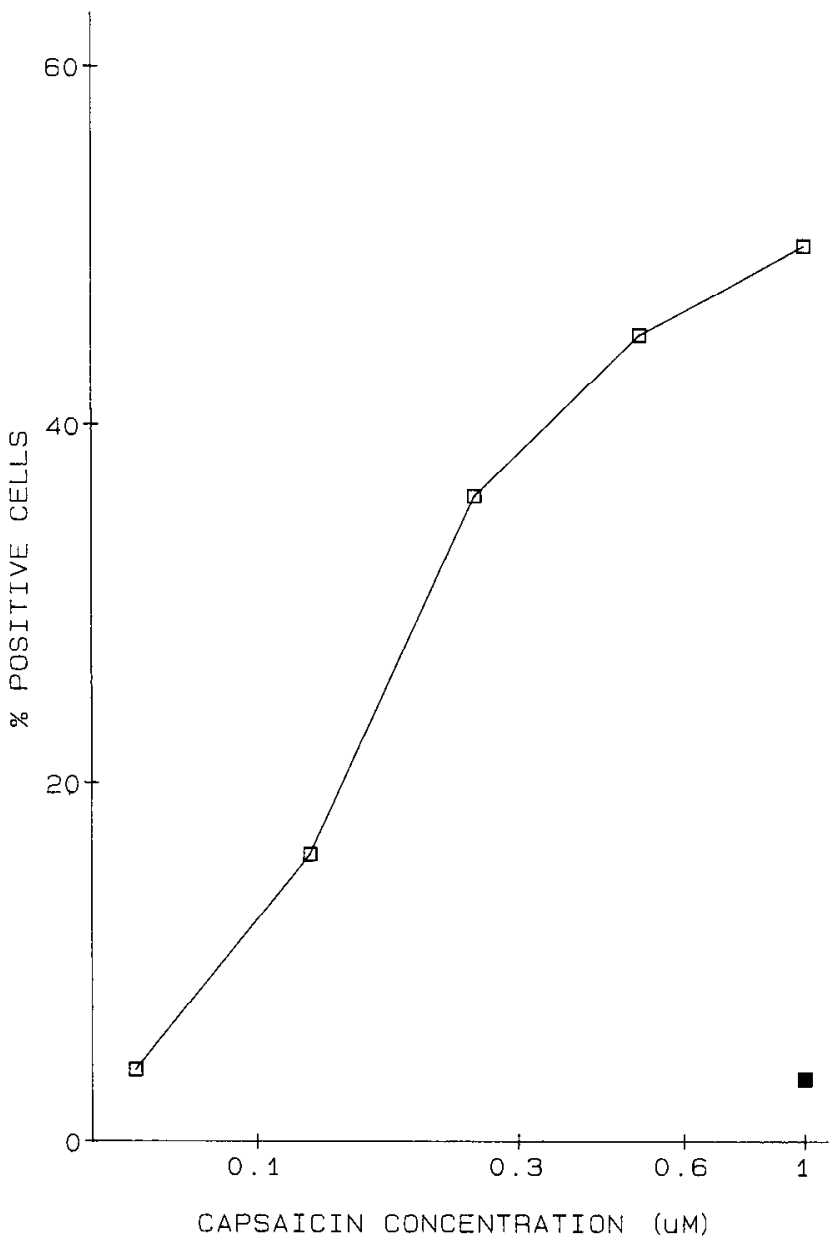

Figure 5. Cobalt uptake detected histochemically upon capsaicin treatment of neonatal rat DRG cells in culture. Neonatal rat DRG cultures (2 DIV) were histochemically stained for capsaicin-dependent cobalt uptake with concentrations of from 0 to $1 \mu \mathrm{M}$ capsaicin. The number of positively stained cells was expressed as a percentage of the total neurons present in a Terasaki plate well. A single, representative experiment is shown. Maximal uptake levels varied depending on the time in culture (see Results). $\mathrm{EC}_{50}=0.2 \mu \mathrm{M}$. (Background uptake, filled square).

on a subpopulation of DRG neurons (Jancso et al., 1977, 1985; Hoyes and Barber, 1981; Hogan, 1988).

Prolonged exposure to micromolar concentrations of capsaicin also abolished the subsequent ion fluxes elicited by capsaicin. No capsaicin-evoked fluxes of ${ }^{45} \mathrm{Ca},{ }^{22} \mathrm{Na},{ }^{14} \mathrm{C}$ guanidine, or ${ }^{86} \mathrm{Rb}$ were seen in cultures that had been exposed to $2 \mu \mathrm{M}$ capsaicin overnight and then washed extensively over $2-5 \mathrm{hr}$ before assay (see, for example, Fig. $4 B$ ).

Responses of DRG neurons from other species and of other cell types. Although the excitatory and toxic effects of capsaicin are confined to a subset of rat DRG neurons, a variety of membrane effects have been reported in different types of neurons (Dubois, 1982; Williams and Ziegelgansberger, 1982; Erdelyi and Such, 1984; Petersen et al., 1984; Dunlap, 1985; Heyman and Rang, 1985).

Capsaicin-evoked calcium fluxes were studied in cultures of rat sciatic nerve, which contain fibroblasts and Schwann cells that are also found in the cultures of DRG neurons. No fluxes were elicited by capsaicin over the concentration range $10 \mathrm{nM}$ to $10 \mu \mathrm{M}$ (Fig. $8 A$ ), which is consistent with the failure to observe any evoked fluxes in "capsaicin-killed" cultures. Figure $8 A$ also shows that capsaicin does not evoke a ${ }^{45} \mathrm{Ca}$ influx in cultures of neonatal rat SCG neurons. In addition to its cell-type specificity, capsaicin responsiveness also depended on the species of animal. Whereas cultured DRG neurons from mouse showed a good response to capsaicin, with an $\mathrm{EC}_{50}$ for calcium uptake of 0.2 $\mu \mathrm{M}$ (data not shown), cultured chick DRG neurons failed to respond (Fig. $8 B$ ).

We also used the calcium and guanidine flux assays to investigate the capsaicin responsiveness of a number of neuronal cell lines (NG108.15, N18TG2, PC12, NG115.401L, F1D7, $\mathrm{B} 2 \mathrm{~A} 5, \mathrm{~F} 2 \mathrm{C} 3, \mathrm{~B} 1 \mathrm{~B} 2, \mathrm{~F} 9)$ in the hope of identifying sensitive cell lines that would facilitate a biochemical analysis of capsaicin action. Some of the cell lines tested were hybrids derived form DRG $\times$ neuroblastoma or DRG $\times$ embryonal carcinoma fusions (Minna et al., 1971; Greene and Tischler, 1976; Hamprecht, 1977; Nicolas et al., 1978; Dickson et al., 1983; Liesi et al., 1983). No significant capsaicin-evoked calcium or guanidine fluxes were noted in these cell lines, irrespective of whether or not they were induced to differentiate by either addition of dibutyryl-cAMP or retinoic acid or by growth in low-serum conditions.

\section{Discussion}

Capsaicin exerts excitatory and toxic actions on a subset of neurons that includes the polymodal nociceptors. Capsaicin itself induces the sensation of pain, and it is therefore possible that understanding the basis of the specificity of mechanism of action of capsaicin will shed light on the mechanism of activation of polymodal nociceptors by other noxious stimuli.

In the present study, we have characterized some of the shortterm biochemical events induced by capsaicin in cultured DRG neurons. Cultured sensory neurons and isolated DRGs have been shown to respond to capsaicin by depolarization (Baccaglini and Hogan, 1983; Heyman and Rang, 1985), and to undergo osmotic and calcium-mediated forms of damage culminating in depth upon long-term capsaicin application (Jancso et al., 1977, 1985; Lawson and Harper, 1984; Hogan, 1988). We have quantitatively investigated capsaicin-induced sodium, calcium, rubidium, and chloride ion fluxes in cultured sensory neurons and other cell types. It was important at the outset to obtain evidence that the cultured cells that we were investigating retained properties expressed in vivo. DRG neurons have been classified according to a number of functional and anatomical criteria (Lieberman, 1976). One such scheme defines 2 populations of neurons, which differ on the basis of cell body diameter, microscopic appearance, cytoskeletal content, action potential duration, and conduction velocity (Andres, 1961; Yamadori, 1971; Lieberman, 1976). Cells of the large, light population are rich in neurofilaments and represent the fast-conducting myelinated mechanoreceptive and thermoreceptive A-type sensory neuron population. The small, dark cell population contains no detectable neurofilaments upon immunocytochemical or electronmicroscopic examination, and includes the polymodal nociceptors, with unmyelinated, slowly conducting $C$ fibers that display long action potential durations. Morphometric studies in vivo have demonstrated overlap in the size distributions of these 2 distinct populations, and have also demonstrated that although capsaicin is toxic mainly to unmyelinated $\mathrm{C}$ fibers, a small number of myelinated afferents, some of which fall into the large, light class of DRG neurons, may also be affected (Lawson and Harper, 1984). We have found that most cultured sensory neu- 

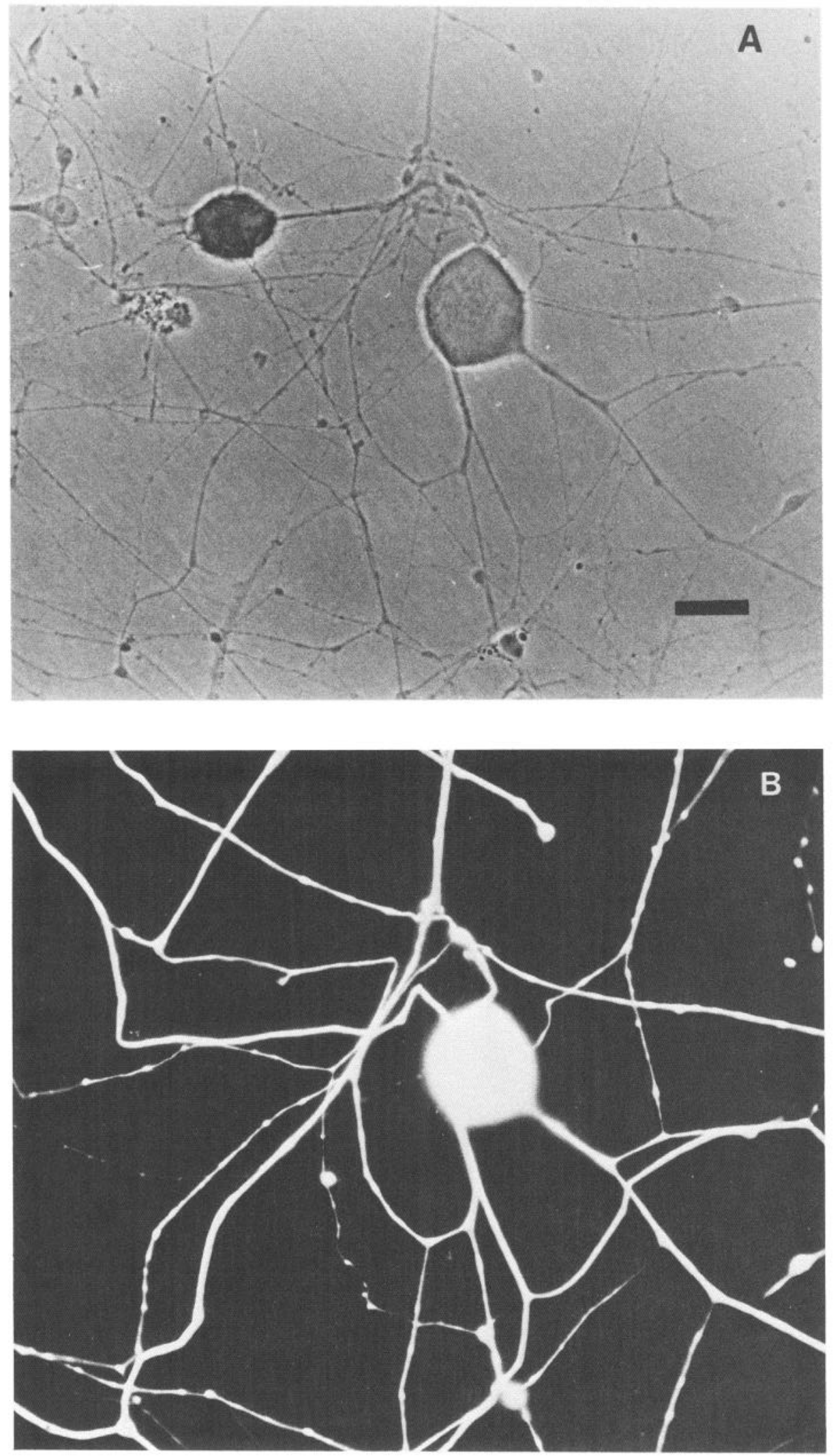

Figure 6. An histochemical demonstration of capsaicin-sensitive DRG neurons in culture; lack of overlap with neurofilament-containing neurons. $A$, Phase-contrast micrograph of a cobaltstained capsaicin-sensitive neuron in a field also containing a capsaicin-insensitive unstained neuronal cell body ( 7 DIV). $B$, Identical field examined by epifluorescence microscopy after staining with an anti-neurofilament monoclonal antibody (RT97) and fluorescein-labeled anti-mouse antisera. Note the presence of immunoreactive material within the capsaicin-insensitive neuronal cell body and processes, and the absence of staining of the capsaicinsensitive cell. Bar, $25 \mu \mathrm{M}$. 

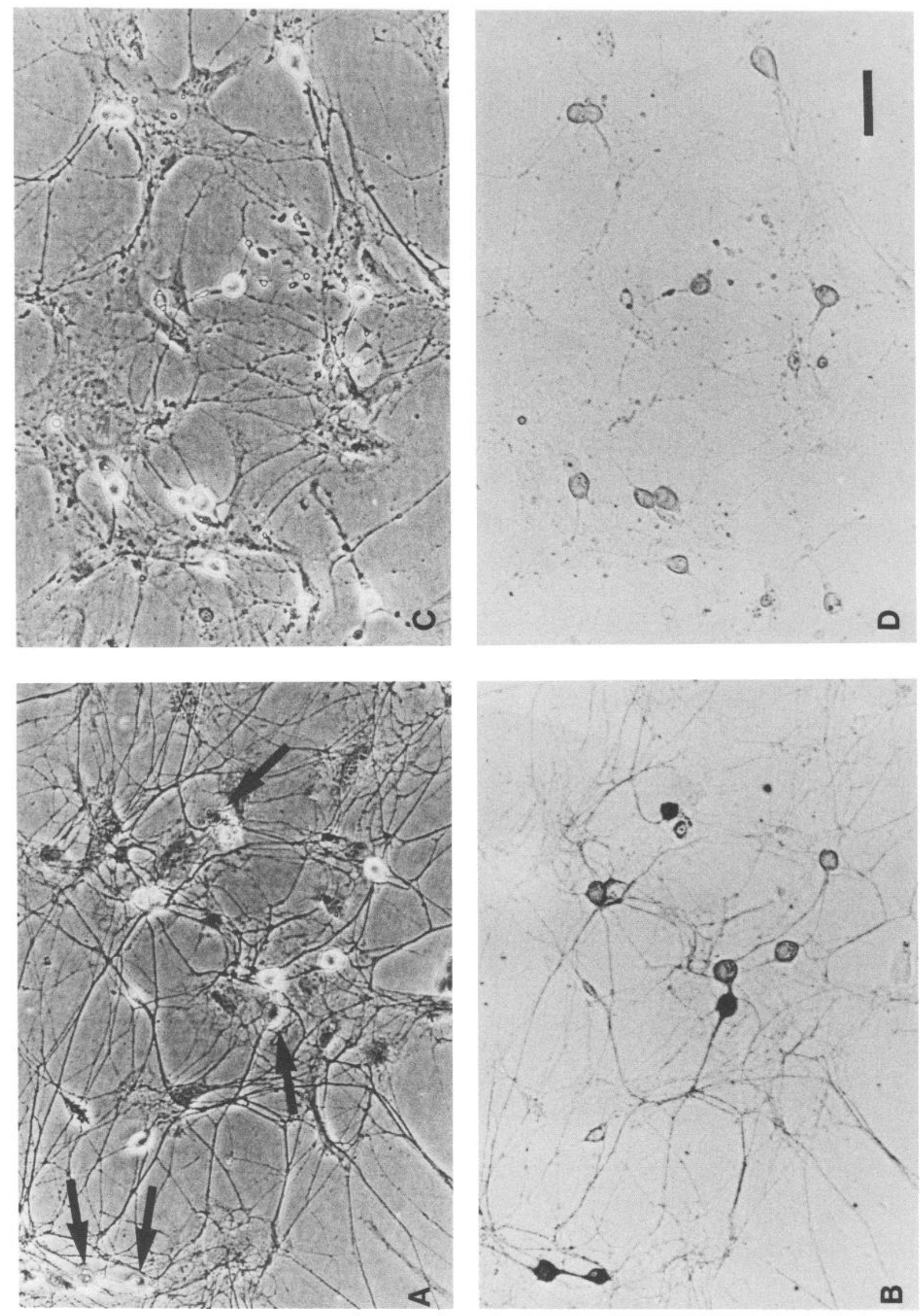

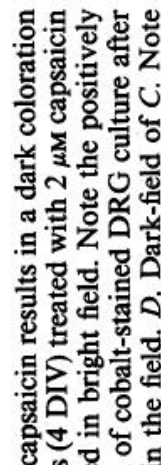

웡

80

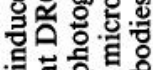

政

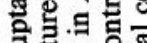

항 훙

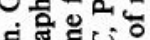

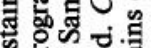
ब. 家 응

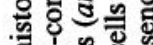

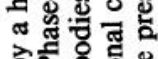

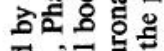
हैं चै

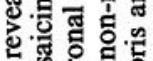
s. 을

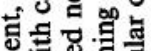

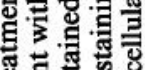
政 a 包焉 क्ष . 응 함응 do 을 응

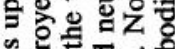
$\overline{\bar{z}} \mathrm{~s} . \overline{\mathrm{s}}$

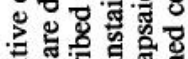
咜

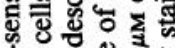

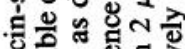
留 ⿶凵 드읭

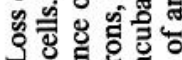
政 근

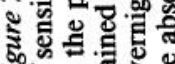

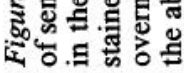




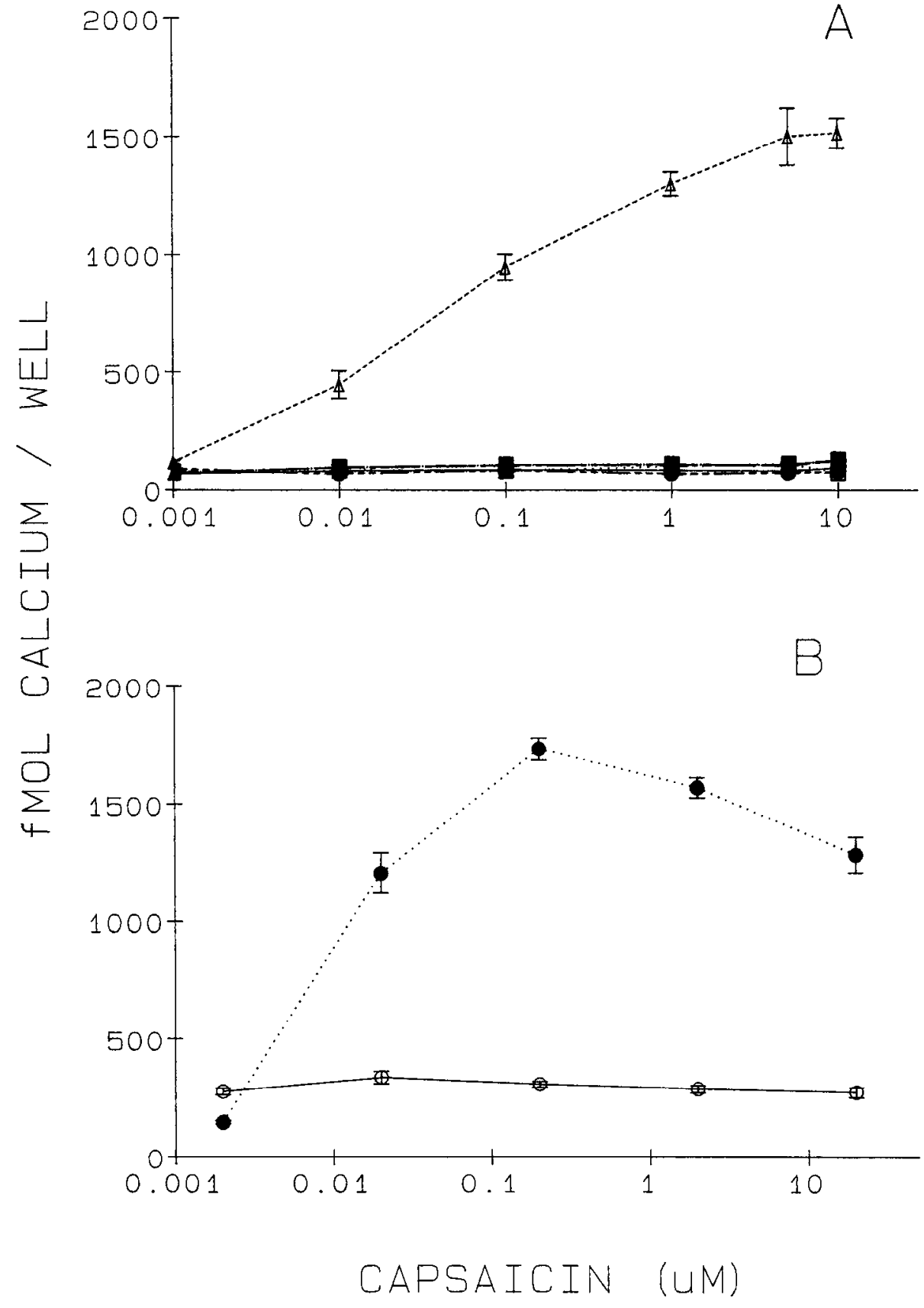

Figure 8. Species and cell-type specificity of capsaicin-induced ${ }^{45} \mathrm{Ca}$ uptake. $A,{ }^{45} \mathrm{Ca}$ uptake into primary cultures of rat DRG neurons (----- $\triangle-\cdot-\cdot-)$ SCG neurons (---------), non-neuronal cells from sciatic nerve (-0), non-neuronal cells derived from DRGs (-.- - - - - ), and overnight capsaicin-treated $(2 \mu \mathrm{M})$ rat DRG cultures $(\cdots \cdots \square \cdots \cdots) .\left(n=3,3-5\right.$ DIV. $B,{ }^{45} \mathrm{Ca}$ accumulation over a $10 \mathrm{~min}$ period was measured in the presence of varying doses of capsaicin in primary cultures of chick and rat DRG cells. $(n=3,3-5$ DIV.) (@), Rat DRG cultures; (O), chick DRG cultures. rons that are sensitive to capsaicin do not contain immunoreactive neurofilamentous material. This mirrors the situation observed in vivo (Lawson and Harper, 1984).

\section{Cellular specificity of capsaicin action}

The quantitative nature of the calcium accumulation assay, discussed below, has allowed us to investigate the cellular and species specificity of this action of capsaicin in cultured cells. The absence of any action on cultured chick DRG neurons is consistent with the failure of birds in general to show antinociceptive or irritant capsaicin effects (Szolcsanyi et al., 1986). Similarly, sympathetic neurons from the rat SCG show no detectable calcium uptake responses to capsaicin. Non-neuronal primary cultures of fibroblasts or Schwann cells derived from DRGs or the sciatic nerve are also insensitive to capsaicin action.
A sensitive cell line would be invaluable as an aid in the analysis of biochemical events induced by capsaicin. For this reason, we screened a number of cell lines for capsaicin-induced toxicity, calcium uptake, or cobalt staining. A number of neural crest-derived neuroblastoma lines (Hamprecht, 1977; Hatanaka and Amano, 1981), as well as hybrids derived from pluripotent embryonal carcinoma cells (Nicolas et al., 1978; Dickson et al., 1983), were found to be negative in all assays used, whether or not the cells were differentiated. Attempts to identify or generate capsaicin-sensitive cell lines are continuing.

\section{Capsaicin-induced calcium accumulation}

Capsaicin induces a very high level of calcium accumulation into sensory neurons in culture. Calculations based on cell volume, derived from measurements of cell diameter, and the specific activity of the ${ }^{45} \mathrm{Ca}$ used show that the additional accu- 
mulation of calcium may be as large as $12 \mathrm{mmol} /$ liter in sensitive neurons. These calculations assume that the neurite volume is negligible, although, with a total neurite length of $1 \mathrm{~mm} /$ cell, the final concentration of calcium would be approximately halved. The destination of this calcium is almost certainly the mitochondria, as inhibitors of reticular calcium buffering such as methylxanthines have no effect, while the mitochondrial uptake blocker ruthenium red is a potent antagonist of capsaicininduced calcium uptake. The uptake of calcium into the mitochondria of sensitive cells depends on the provision of ATP or a functional respiratory chain (Lehninger et al., 1967). The relatively high levels of uptake at low temperatures are probably due to the utilization of intracellular ATP stocks. These results should be considered within the context of earlier reports of mitochondrial swelling and ultrastructural damage in sensory neurons of capsaicin-treated animals (Joo et al., 1969; Szolcsanyi et al., 1971). In addition, other workers have demonstrated in semiquantitative fashion the capsaicin-induced uptake of calcium into DRG neurons (Jancso et al., 1984).

\section{Nature of the calcium channel}

Does calcium enter the cell through a voltage-sensitive calcium channel? Three different voltage-sensitive calcium channels (L, $\mathrm{N}$, and $\mathrm{T}$ ) have been defined in chick DRG neurons on the basis of their channel, activation, and inactivation characteristics (Nowycky et al., 1985a, b). In a variety of central neurons, both voltage-sensitive and receptor-operated calcium channel fluxes have been detected (Miller, 1987a, b). Because $\mathrm{KCl}$-induced depolarization causes at most a 2-fold increase in calcium influx into rat DRG neurons, compared to 10-20 fold with capsaicin, it seems unlikely that capsaicin induces calcium uptake primarily though a voltage-sensitive calcium channel, although such channels are presumably activated by capsaicin-induced depolarization. Thus, the capsaicin-activated calcium channel is unlikely to correspond to a known voltage-sensitive calcium channel, a result confirmed by our failure to inhibit calcium accumulation with a variety of calcium channel antagonists. Cinnarizine, a specific blocker of calcium channels that differs from nifedipine and verapamil in not acting on slow myocardial calcium conductances, inhibits calcium uptake induced by capsaicin after a long preincubation, but not when incubated together with capsaicin. Trifluoperazine also inhibits capsaicininduced calcium uptake, possibly through an intracellular mechanism. The basis for the inhibition of calcium uptake by high concentrations of these agents is unclear.

How can we rationalize the massive level of calcium accumulation caused by capsaicin is susceptible cells? No depolarizing stimulus or endogenous ligand that we tested gave such an effect. Capsaicin induces calcium entry into the cell apparently without compromising the intracellular buffering abilities of the mitochondria. This action, coupled with the cellular specificity of capsaicin, is most easily explained by action at a specific receptor or channel, rather than by a nonspecific ionophoretype action. Whatever its route into the cell, the capsaicin-evoked uptake is clearly not shut down until massive levels of accumulation have occurred. This may even reflect the saturation of the cell's calcium-buffering capacity, although the different levels of calcium accumulated after $10 \mathrm{~min}$, when incubations are carried out with different concentrations of external calcium, suggest that other mechanisms, such as desensitization, may also operate.
The $\mathrm{EC}_{50}$ for capsaicin-induced calcium uptake is $0.2 \mu \mathrm{M}$, which is identical to the figure determined for the capsaicintreated rat eye-wipe assay (Szolcsanyi and Jancso-Gabor, 1975), giving further support to the usefulness of cultured sensory neurons as a reliable system for elucidating the mechanism of capsaicin action in vivo.

\section{Other capsaicin-induced ion fluxes}

Sodium or guanidine uptake is increased by capsaicin, although to a much smaller extent than calcium uptake, presumably because neither is accumulated by intracellular buffers; but the $\mathrm{EC}_{50}$ for both is about $0.06 \mu \mathrm{M}$, somewhat lower than that for calcium uptake. It is possible that this difference reflects the complexity of the various mechanisms for extruding intracellular calcium, rather than a real difference in potency. Calcium accumulation into mitochondria occurs in the presence of micromolar levels of free intracellular calcium (Crompton, 1985). Plasma membrane pumps many maintain free intracellular calcium at levels below this with an $\mathrm{EC}_{50}$ dose of capsaicin, but with higher capsaicin doses, may be overwhelmed, allowing a substantial accumulation of calcium into the mitochondria to occur. In support of this argument, the $\mathrm{EC}_{50}$ for capsaicin-induced cGMP elevation (a calcium-dependent process; J. N. Wood, P. R. Coote, A. Minhas, I. Mullaney, M. McNeill, and G. Burgess, unpublished observations is $0.07 \mu \mathrm{M}$ ).

The fact that no chloride efflux occurs upon capsaicin treatment under conditions in which GABA can evoke a significant response suggests that capsaicin does not cause a nonspecific increase in permeability, but specifically affects cation conductances.

Rubidium cfflux, although not representing the total flux of potassium ions (Peterson and Maruyama, 1984), is frequently used as a measure of potassium fluxes. Capsaicin induces a rubidium efflux $\left(\mathrm{EC}_{50}=0.06 \mu \mathrm{M}\right)$ that is lowered in the absence of extracellular calcium. Capsaicin therefore probably opens calcium-activated potassium channels. Such conductances are also activated by depolarizing stimuli but require calcium binding to the $\mathrm{K}^{\prime}$ channel (Hille, 1984). In support of the argument that capsaicin does depolarize cells in the absence of external calcium is the finding that guanidine fluxes are detectable in calcium-free EGTA-containing solutions.

The massive accumulation of calcium detected in vitro bears on a number of capsaicin-induced phenomena observed in vivo. For example, the release of neuropeptides and the inhibition of axoplasmic transport (Gamse et al., 1982; McDougal et al., 1983; Taylor et al., 1984) may well be consequences of calcium uptake to pathological levels. Apart from causing osmotic forms of cell damage (Hogan, 1988), calcium-activated proteases and other degradative enzymes would be expected to interfere with cytoskeletal organization and axoplasmic flow (Kamakura et al., 1983). The interruption in the transport of survival factors might then contribute to cell death.

In summary, we have quantitatively analyzed ion fluxes induced by capsaicin and confirmed the usefulness of cultured sensory neurons as a relevant system with which to study the mechanism of capsaicin action. Capsaicin evokes calcium and sodium uptake into a subset of sensory neurons, and an efflux of rubidium - an index of potassium flux. These experiments provide quantitative tests with which to identify endogenous or synthetic capsaicin agonists and antagonists, as well as to define the locus of capsaicin action itself. 


\section{References}

Andres, K. H. (1961) Untersuchungen über den Feinbau von Spinalganglien. Z. Zellforsch. Mikrosk. Anat. 55: 1-48.

Baccaglini, P. I., and P. G. Hogan (1983) Some rat sensory neurons in culture express characteristics of differentiated pain sensory neurons. Proc. Natl. Acad. Sci. USA 80: 594-598.

Baker, P. F., and J. A. Umbach (1987) Calcium buffering in axons and axoplasm of Loligo. J. Physiol. (Lond.) 383: 369-394

Bevan, S. J., I. F. James, H. P. Rang, J. Winter, and J. N. Wood (1987) The mechanism of action of capsaicin - a sensory neurotoxin. In $\mathrm{Neu}$ rotoxins and their Pharmacological Implications, P. Jenner, ed., pp. 261-277, Raven, New York.

Broekemeier, K. M., P. C. Schmid, H. H. O. Schmid, and D. R. Pfeiffer (1985) Effects of phospholipase A2 inhibitors on ruthenium red induced calcium release from mitochondria. J. Biol. Chem. 260: 105113.

Carpenter, S. E., and B. Lynn (1981) Vascular and sensory responses of human skin to mild injury after topical treatment with capsaicin. Br. J. Pharmacol. 73: 755-758.

Coleridge, H. M., J. C. Coleridge, and J. C. Luck (1965) Pulmonary efferent fibres of small diameter stimulated by capsaicin and by hyperinflation of the lungs. J. Physiol. (Lond.) 179: 248-262.

Crompton, M. (1985) The regulation of mitochondrial calcium transport in heart. In Current Topics in Membranes and Transport, vol. 25, F. Bronner and A. E. Shamoo, eds., pp. 231-276, Academic, New York.

Dickson, J. G., T. P. Flanigan, and F. Walsh (1983) Expression of human neuronal antigens in a mouse neuroblastoma $\times$ human dorsal root ganglion cell hybrid. EMBO J. 2: 283-288.

Dubois, J. M. (1982) Capsaicin blocks one class of $\mathrm{K}^{+}$channels in the frog node of Ranvier. Brain Res. 245: 372-375.

Dunlap, K. (1985) Forskolin prolongs action potential duration and blocks potassium currents in embryonic chick sensory neurons. Pfluegers Arch. 403: 170-174.

Erdelyi, L., and G. Such (1984) The effects of capsaicin on action potential and outward potassium currents in the bursting neurone of the snail. Neurosci. Lett. 55: 71-76.

Fitzgerald, M. (1983) Capsaicin and sensory neurones - a review. Pain 15: $1109-1130$.

Gamse, R. (1982) Capsaicin and nociception in the rat and mouse. Possible role of substance P. Naumyn Schmiedeberg's Arch. Pharmacol. 320: 205-216.

Gamse, R., A. Molnar, and F. Lembeck (1979) Substance P release from spinal cord slices by capsaicin. Life Sci. 25: 629-636.

Gamse, R., U. Petsche, F. Lembeck, and G. Jancso (1982) Capsaicin applied to peripheral nerve inhibits axoplasmic transport of substance $\mathrm{P}$ and somatostatin. Brain Res. 239: 447-462.

Godfraind, T. (1987) Classification of calcium antagonists. Am. J. Cardiol. 59: 11b-23b.

Godfraind, J. M., T. M. Jessell, J. S. Kelly, R. N. McBurney, A. W. Mudge, and M. Yamamoto (1981) Capsaicin prolongs action potential duration in cultured sensory neurones. J. Physiol. (Lond.) 312 : 32-33.

Greene, L., and A. S. Tischler (1976) Establishment of a noradrenergic clonal line of rat adrenal pheochromocytoma cells which respond to NGF. Proc. Natl. Acad. Sci. IJSA 73: 2424-2428.

Hamprecht, B. (1977) Structural, electrophysiological, biochemical and pharmacological properties of neuroblastoma-glioma cell hybrids in cell culture. Int. Rev. Cytol. 490: 99-170.

Handwerker, H. O., U. Holzer-Petsche, C. Heym, and E. Welk. (1984) $\mathrm{C}$-fibre functions after topical application of capsaicin to a peripheral nerve and neonatal capsaicin treatment. In Antidromic Vasodilatation and Neurogenic Inflammation, L. A. Chahl, J. Szolcsanyi, and F. Lembeck, eds., pp. 57-79, Akademiai Kiado, Budapest.

Hatanaka, H., and T. Amano (1981) A mouse neuroblastoma $\times$ rat glioma hybrid cell produces immunoreactive substance P-like material. Brain Res. 215: 305-316.

Hayes, A. G., and M. B. Tyers (1980) Effects of capsaicin on nociceptive heat, pressure and chemical thresholds and on substance $\mathbf{P}$ levels in the rat. Brain Res. 189: 561-564.

Heyman, I., and H. P. Rang (1985) Depolarising responses to capsaicin in a subpopulation of rat dorsal root ganglion cells. Neurosci. Lett. 56: $69-75$.
Hille, B. (1984) Ionic channels of excitable membranes. Sinauer, Sunderland, MA.

Hogan, P. (1983) Expression of markers for pain sensory neurons in cell culture. Ph.D. thesis, Harvard University.

Hogan, P. (1988) Mechanisms by which capsaicin produces damage in neurons cultured from rat sensory ganglia. J. Neurosci. (in press).

Hoyes, A. D., and P. Barber (1981) Degeneration of axons in the uretenic and duodenal nerve plexuses of the adult rat following in vivo treatment with capsaicin. Neurosci. Lett. 25: 19-24.

Jancso, G. (1984) Sensory nerves as modulators of inflammatory reactions. In Antidromic Vasodilatation and Neurogenic Inflammation, L. A. Chahl, J. Szolcsanyi, and I. Lembeck, eds., pp. 207-222, Akademiai Kiado, Budapest.

Jancso, G., and G. Such (1983) Effects of capsaicin applied perineurally to the vagus nerve on cardiovascular and respiratory functions in the cat. J. Physiol. (Lond.) 341: 359-370.

Jancso, G., E. Kiraly, A. Jancso-Gabor (1977) Pharmacologically induced selective degeneration of chemosensitive primary neurones. Nature 270: 741-743.

Jancso, G., S. Karcsu, E. Kiraly, A. Szebeni, L. Toth, E. Bacsy, F. Joo, and A. Parducz (1984) Neurotoxin induced nerve cell degencration: Possible involvement of calcium. Brain Res. 295: 211-216.

Jancso, G., E. Kiraly, F. Joo, G. Such, and A. Nagy (1985) Selective degeneration by capsaicin of a subpopulation of primary sensory neurons in the adult rat. Neurosci. Lett. 59: 209-214.

Joo, F., J. Szolcsanyi, and A. Jancso-Gabor (1969) Mitochondrial alterations in the spinal ganglion cells of the rat accompanying the long-lasting sensory disturbances induced by capsaicin. Life Sci. 8: $621-626$.

Kamakura, K., S. Ishiura, H. Sugita, and Y. Toyokura (1983) Identification of calcium activated neutral protease in the peripheral nerve and its effect on neurofilament degeneration. J. Neurochem. 40: 908913.

Kao, C. Y., and A. Nishiyama (1965) Actions of saxitoxin on peripheral neuromuscular systems. J. Physiol. (Lond.) 180: 50-66.

Kenins, P. (1982) Responses of single nerve fibres to capsaicin applied to the skin. Neurosci. Lett. 29: 83-88.

Konietzny, F., and H. Hensel (1983) The effects of capsaicin on the response characteristic of human $\mathrm{C}$-polymodal nociceptors. J. Therm. Biol. 8: 213-215.

Lawson, S. N., and A. A. Harper (1984) Neonatal capsaicin is not a specific neurotoxin for sensory C-fibres or small dark cells of rat dorsal root ganglia. In Antidromic Vasodilatation and Neurogenic Inflammation, L. A. Chahl, J. Szolcsanyi, and F. Lembeck, eds., pp. 111117, Akademiai Kiado, Budapest.

Lawson, S. N., A. A. Harper, E. I. Harper, J. A. Garson, and B. H. Anderton (1984) A monoclonal antibody against neurofilament protein specifically labels a sub-population of rat sensory neurones. J. Comp. Neurol. 228: 263-272.

Lehninger, A. L., E. Carafoli, and C. S. Rossi (1967) Energy-linked ion movements in mitochondrial systems. Adv. Enzymol. 29: 259320.

Lembeck, F., and R. Gamse (1982) Substance $P$ in peripheral sensory processes. In Substance P in the Nervous System (CIBA Symp. 91), pp. 35-54, Pitman, London.

Lieberman, A. R. (1976) Sensory ganglia. In The Peripheral Nerve, D. N. Landon, ed., pp. 178-188, Chapman and Hall, London.

Liesi, P., L. Reichardt, and J. Wartiovaara (1983) Nerve growth factor induces adrenergic neuronal differentiation in F9 teratocarcinoma cells. Nature 306: 265-267.

Lindsay, R. (1988) Nerve growth factors (NGF, BDNF) enhance axonal regeneration but are not required for survival of adult sensory neurons. J. Neurosci. (in press).

Lundberg, J. M., A. Saria, E. Theodorsson-Norheim, E. Brodin, X. Hua, C.-L. Martling, R. Gamse, and T. Hökfelt (1985) Multiple tachykinins in capsaicin-sensitive afferents: Occurrence, release and biological effects with special reference to irritation of the airways. In Tachykinin Antagonists, R. Hakanson and F. Sundler, eds., pp. 159197, Elsevier, Amsterdam.

Lynn, B., S. E. Carpenter, and A. Pini (1984) Capsaicin and cutaneous afferents. In Neurogenic Inflammation, L. A. Chahl, I. Szolcsanyi, and F. Lembeck, eds., pp. 83-93, Akademiai Kiado, Budapest.

McDougal, D. B., M. J. C. Yuan, R. V. Dargar, and E. M. Johnson (1983) Neonatal capsaicin and guanethidine and axonally trans- 
ported organelle-specific enzymes in sciatic nerve and in sympathetic and dorsal root ganglia. J. Neurosci. 3: 124-132.

Micevych, P. E., T. L. Yaksh, and J. Szolcsanyi (1983) Effect of intrathecal capsaicin analogues on the immunofluorescence of peptides and serotonin in the dorsal horn in rats. Neuroscience 8: 123-131.

Miller, R. (1987a) Calcium channels in neurones. In Structure and Physiology of the Slow Inward Calcium Channel: Receptor Biochemistry and Methodology, D. J. Triggle and J. C. Venter, eds., vol. 9, pp. 67-83, Liss, New York.

Miller, R. (1987b) Multiple calcium channels and neuronal function. Science 235: 46-52.

Minna, J., P. G. Nelson, J. Peacock, D. Glazer, and M. Niremberg (1971) Genes for neuronal properties expressed in neuroblastoma $\times$ L cell hybrids. Proc. Natl. Acad. Sci. USA 68: 234-239.

Nagy, J. I., and D. van der Kooy (1983) Effects of neonatal capsaicin treatment on nociceptive thresholds in the rat. J. Neurosci. 3:11451150 .

Neering, I. R., and R. N. McBurney (1984) Role for microsomal calcium storage in mammalian neurones. Nature 309: 158-160.

Nicolas, J.-F., H. Jakob, and F. Jacob (1978) Metabolic cooperation betwecn mousc embryonal carcinoma cells and their differentiated derivatives. Proc. Natl. Acad. Sci. USA 75: 3292-3296.

Nowycky, M. C., A. P. Fox, and R. W. Tsien (1985a) Three types of neuronal calcium channel with different calcium agonist sensitivity. Nature 316: 440-443.

Nowycky, M. C., A. P. Fox, and R. W. Tsien (1985b) Long opening mode of gating of neuronal calcium channels and its promotion by the dihydropyridine calcium agonist Bay K8864. Proc. Natl. Acad. Sci. USA 82: 2178-2182.

Petersen, M., M. Weyrich, and F.-K. Pierau (1984) Effect of capsaicin on sodium and potassium channels of sensory neurones of rodents and chicken. Neurosci. Lett. (Suppl. 18): S151.

Peterson, O. H., and Y. Maruyama (1984) Calcium-activated potassium channels and their role in secretion. Nature 307:693-696.

Pricstlcy, J. V., S. Bramwell, L. Butcher, and A. C. Cuello (1982) Effects of capsaicin on neuropeptides in areas of termination of primary sensory neurones. Neurochem. Int. 4: 57-66.

Schramm, M., G. Thomas, R. Towart, and G. Franckowiak (1983) Novel dihydropyridines with positive inotropic action through activation of calcium channels. Nature 303: 535-537.
Szolcsanyi, J. (1983) Capsaicin: Hot new pharmacological tool. Trends Neurosci. 4: 495-497.

Szolcsanyi, J. (1984) Capsaicin sensitive chemoreceptive neural system with dual sensory efferent function. In Antidromic Vasodilatation and Neurogenic Inflammation, L. A. Chahl, J. Szolcsanyi, and F. Lembeck, eds., pp. 27-55, Akademiai Kiado, Budapest.

Szolcsanyi, J. (1985) Sensory receptors and the antinociceptive effects of capsaicin. In Tachykinin Antagonists, R. Hakanson and F. Sundler, eds., pp. 45-54, Elsevier, Amsterdam.

Szolcsanyi, J., and A. Jancso-Gabor (1975) Sensory effects of capsaicin congenors. Arzneimmittelforsch. 25: 1877-1881.

Szolcsanyi, J., F. Joo, and A. Jansco-Gabor (1971) Mitochondrial changes in preoptic neurones after capsaicin desensitization of the hypothalamic thermodetectors in rats. Nature 229: 116-1 17.

Szolcsanyi, J., H. Sann, and F. K. Pierau (1986) Nociception in pigeons is not impaired by capsaicin. Pain 27: 247-260.

Taylor, D. C. M., F.-K. Pierau, and J. Szolcsanyi (1984) The effect of capsaicin on axoplasmic transport in a rat peripheral nerve. In $A n$ tidromic Vasodilatation and Neurogenic Inflammation, L. A. Chahl, F. Szolcsanyi, and F. Lembeck, eds., pp. 165-172, Akademiai Kiado, Budapest.

Webb, M., C. Graham, and F. Walsh (1986) Neuronal differentiation of cloned human teratoma cells in response to retinoic acid in vitro. J. Neuroimmunol. 11: 67-86.

Wieraszko, A. (1986) Evidence that ruthenium red disturbs the synaptic transmission in the rat hippocampal slices through interacting with sialic acid residues. Brain Res. 378: 120-126.

Williams, J. T., and W. Zieglgansberger (1982) The acute effects of capsaicin on rat primary afferents and spinal neurones. Brain Res. 252: $125-131$

Winter, J. (1987) Characterisation of capsaicin-sensitive neurons in adult dorsal root ganglion cultures. Neurosci. Lett. 80: 134-140.

Wood, J. N., and B. H. Anderton (1981) Monoclonal antibodies to mammalian neurofilaments. Biosci. Rep. 1: 263-268.

Yamadori, T. (1971) A light and electron microscopic study on the postnatal development of spinal ganglia. Acta Anat. Nippon 45: 191205. 